\title{
Development of new DMAP-related organocatalysts for use in the Michael addition reaction of $\beta$-ketoesters in water
}

Kyungmin Ko, Keiji Nakano, Shigeru Watanabe, Yoshiyasu Ichikawa, Hiyoshizo Kotsuki*

Laboratory of Natural Product Chemistry, Faculty of Science, Kochi University, Akebono-cho, Kochi 780-8520, Japan

*Corresponding authors. Tel.: +81 88844 8298; fax: +81 888448359

E-mail address: kotsuki@kochi-u.ac.jp

\begin{abstract}
:
A general and efficient protocol for the Michael addition reactions of $\beta$-ketoesters in pure water has been developed. The reactions are successfully catalyzed by newly designed DMAP-related organocatalysts such as 4-(didecylamino)pyridine, and the desired Michael adducts are obtained in good to high yields
\end{abstract}

Keywords:

Michael addition reaction; $\beta$-Ketoesters; DMAP-related organocatalyst, Aqueous media

Organic reactions in water have received considerable attention from synthetic chemists, since they are environmentally clean, non-toxic and inexpensive. ${ }^{1}$ In particular, over the past decade remarkable progress has been achieved in the field of organocatalytic transformations ${ }^{2}$ in aqueous media as a primary contribution to "green chemistry"., ${ }^{3,4}$ However, there are still some limitations on the availability of organocatalysts and the versatility of reactions that might be effective "in pure water".

In designing new water-tolerant organocatalysts, we were interested in the unique base character of 4-(dimethylamino)pyridine (DMAP, $\mathrm{pK} K_{\mathrm{a}} 9.70$ in $\left.\mathrm{H}_{2} \mathrm{O}\right){ }^{5}$ Since its discovery in the late 1960's, ${ }^{6}$ DMAP and related compounds have been used in several areas of organic synthesis, including carbon-carbon bond-forming reactions. ${ }^{7}$ As a consequence, recent works by Barbas, ${ }^{8}$ Benaglia, ${ }^{9}$ Palomo, ${ }^{10}$ Luo, ${ }^{11}$ Carter, ${ }^{12}$ and Nájera ${ }^{13}$ prompted us to develop new types of DMAP-related organocatalysts. We thought that the incorporation of a hydrophobic alkyl side chain on a DMAP core would produce novel catalysts that might be valuable for Michael addition reactions in water. We describe here the realization of this expectation.

The Michael addition reaction is widely recognized as one of the most important carbon-carbon bond-forming reactions in organic synthesis. ${ }^{14}$ This type of reaction is 
generally carried out using strong base metal reagents in organic solvents, such as THF, DMF, or DMSO under dry conditions.

To confirm the feasibility of our catalyst design concept, we prepared a variety of DMAP-related molecules, starting from commercially available aminopyridines, that have different chain lengths and regioisomeric components. We then performed catalytic studies of the Michael addition reaction of ethyl acetoacetate (1a) with methyl acrylate (2a, 4 equiv) in water, in the absence of cosolvents. The results are summarized in Table 1.

$<$ Table $1>$

As expected, we found that the catalytic activities of 3a-i were significantly influenced by the size and position of an alkylamine scaffold. Thus, 4-(didecylamino)pyridine (3d) proved to be the most effective of those screened: in the presence of $10 \mathrm{~mol} \%$ of $\mathbf{3 d}$, the desired double Michael adduct 5 was obtained in almost quantitative yield after stirring for 2 $\mathrm{h}$ at $\mathrm{rt}$ (Table 1, entry 4).

Interestingly, catalysts $\mathbf{3 a}$ and $\mathbf{3} \mathbf{b}$ bearing shorter chain lengths and $3 \mathbf{c}^{15}$ with a single decyl group on 3a were all found to be unfavorable for promoting the desired double Michael addition (Table 1, entries 1-3). Unfortunately, the use of $3 \mathbf{e}^{16}$ mostly gave recovered samples, probably because a $\mathrm{N}\left(\mathrm{C}_{18} \mathrm{H}_{37}\right)_{2}$ group was too large to build up effectively the catalytically active site in this aqueous medium (Table 1, entry 5). The use of regioisomeric catalysts $\mathbf{3 f - i}$ considerably retarded the reaction progress, which indicates that they have a very weak base character in comparison to 3a and 3d (Table 1, entries 6-9). ${ }^{17}$

There was a sharp contrast in the appearance of the reaction mixture in the respective experiments (Figure 1). Thus, while the mixture containing 3d became an emulsion after the first 20-30 min of stirring, other compounds led to a substantially clear heterogeneous phase separation. We supposed that the attachment of two tails of an $n$-decyl chain to a 4-aminopyridine head should be "matched" to form a sort of hydrophobic media in water under such conditions, which allowed efficient catalysis to take place. . $^{8, b, 18,19}$

$<$ Figure $1>$

To obtain further insight into the solvent effect of 3d-catalysis, we performed experiments using methyl cyclopentan-1-one-2-carboxylate (1b) as a Michael donor in various organic and water solvents (Table 2). In THF, $\mathrm{CH}_{2} \mathrm{Cl}_{2}$, and acetonitrile, the reaction proceeded very slowly and gave the adduct $\mathbf{4 b}$ in yields of 59-90\% (Table 2, entries 1-3). The reaction in $\mathrm{MeOH}$ gave results that were almost comparable to those in water, ${ }^{20}$ but the latter solvent was still advantageous with respect to its environmental friendliness and the reaction rate (Table 2, entries 4 and 5). ${ }^{21}$ 
With these results in hand, we then investigated the general scope of this method. Thus, various $\beta$-ketoesters 1 were treated with Michael acceptors 2 in the presence of a catalytic amount of 3d under the standardized conditions. In all of the cases examined, the 3a-catalyzed reactions are also shown for comparison (Table 3).

$<$ Table $3>$

When the reaction of ethyl 2-methylacetoacetate (1c) with 2a was performed in the presence of $10 \mathrm{~mol} \%$ of $\mathbf{3 d}$, the desired adduct $4 \mathbf{c}$ was obtained in $88 \%$ yield after stirring for $7.5 \mathrm{~h}$, while the use of 3a resulted in an incomplete reaction even after $23 \mathrm{~h}$, and gave $4 \mathrm{c}$ in only 15\% yield (Table 3, entries 1 and 2). Very similar behavior was observed for other Michael donors such as ethyl 2-benzylacetoacetate (1d), ethyl 3-oxopentanoate (1e), and ethyl benzoylacetate (1f) and acceptors such as acrylonitrile (2b) (Table 3, entries 3-12). The decreased reactivity of the reactants $\mathbf{1 d - 1 f}$ with their increase in hydrophobicity might be accounted for by the difficulty to cause effective substrate interactions in water. ${ }^{8 \mathrm{a}, \mathrm{b}}$

In the case of 5-membered cyclic $\beta$-ketoester $\mathbf{1 b}, \mathbf{2 b}$ reacted quite smoothly under the catalysis of either 3a or 3d, but better results were obtained with the latter (Table 3, entries 13 and 14). To our surprise, when 2-cyclohexen-1-one (2c) was used as a Michael acceptor, in the presence of $3 \mathbf{a}$ the reaction proceeded very rapidly to afford $\mathbf{4} \mathbf{j}$ in a quantitative yield, whereas 3d showed essentially no catalytic activity even after a prolonged reaction time (Table 3, entries 15 and 16). While we cannot explain this phenomenon at present, we concluded that a cyclic enone system like 2c must have facile mobility to construct a hydrogen-bond aggregation with 3a rather than with 3d in such aqueous media. Methyl propiolate (2d) reacted with $\mathbf{1 b}$ spontaneously in either case (Table 3, entries 17 and 18).

Finally, $\beta$-ketoester $1 \mathrm{~g}$ was also subjected to the above catalytic conversions. In every case we confirmed that the catalyst $3 \mathbf{d}$ gave better results than $3 \mathbf{a}$ with respect to productivity (Table 3, entries 19-22).

In summary, we have developed a new convenient method for the Michael addition reaction of $\beta$-ketoesters by using a novel peacock-shaped organocatalyst $3 \mathbf{d}$ in water as the only solvent. ${ }^{22}$ We believe that the present method offers several advantages in terms of simplicity, readily available reagents, and very mild conditions, and contributes to the development of "green chemistry". Further studies to extend the scope of this new method are now in progress in our laboratory.

\section{Acknowledgment}

This work was supported in part by grants for Scientific Research on Priority Areas (18037053 \& 18032055) from MEXT, as well as by a Special Research Grant for Green 
Science from Kochi University. One of the authors (K. K.) is grateful for a Sasakawa Scientific Research Grant from the Japan Science Society.

\section{Supplementary data}

Experimental procedures and spectral data.

\section{References and notes}

1. (a) Lindström, U. M. Chem. Rev. 2002, 102, 2751; (b) Li, C.-J. Chem. Rev. 2005, 105, 3095; (c) Lindström, U. M., Ed., Organic Reactions in Water, Blackwell: Oxford, 2007; (d) Li, C.-J.; Chan, T.-H. Comprehensive Organic Reactions in Aqueous Media, 2nd Ed., Wiley: Hoboken, 2007; (e) Synlett 2008, Issue 10.

2. (a) Berkessel, A.; Gröger, H. Asymmetric Organocatalysis, Wiley-VCH: New York, 2005; (b) Dalko, P. I., Ed., Enantioselective Organocatalysis, Wiley-VCH: New York, 2007; (c) Chem. Rev. 2007, 107, Issue 12.

3. Sheldon, R. A.; Ardens, I.; Hanefeld, U. Green Chemistry and Catalysis; Wiley-VCH: Weinheim, Germany, 2007.

4. For the controversy regarding organocatalysis in aqueous media, see: (a) Brogan, A. P.; Dickerson, T. J.; Janda, K. D. Angew. Chem. Int. Ed. 2006, 45, 8100; (b) Hayashi, Y. Angew. Chem. Int. Ed. 2006, 45, 8103; (c) Blackmond, D. G.; Armstrong, A.; Coombe, V.; Wells, A. Angew. Chem. Int. Ed. 2007, 46, 3798.

5. Forsythe, P.; Frampton, R.; Johnson, C. D.; Katritzky, A. R. J. Chem. Soc., Perkin Trans. II 1972, 671.

6. (a) Litvinenko, L. M.; Kirichenko, A. I. Dok. Akad. Nauk SSSR, Ser. Khim. 1967, 176, 97; Chem. Abstr. 1968, 68, 68523u; (b) Steglich, W.; Höfle, G. Angew. Chem. Int. Ed. 1969, 8, 981.

7. (a) Höfle, G.; Steglich, W.; Vorbrüggen, H. Angew. Chem. Int. Ed. 1978, 17, 569; (b) Scriven, E. F. V. Chem. Soc. Rev. 1983, 129; (c) Ragnarsson, U.; Grehn, L. Acc. Chem. Res. 1998, 31, 494; (d) Berry, D. J.; Digiovanna, C. V.; Metrick, S. S.; Murugan, R. ARKIVOC 2001 (i), 201; (e) Murugan, R.; Scriven, E. F. V. Aldrichimica Acta 2003, 36, 21; (f) Spivey, A. C.; Arseniyadis, S. Angew. Chem. Int. Ed. 2004, 43, 5436.

8. (a) Mase, N.; Nakai, Y.; Ohara, N.; Yoda, H.; Takabe, K.; Tanaka, F.; Barbas, C. F. III. J. Am. Chem. Soc. 2006, 128, 734; (b) Mase, N.; Watanabe, K.; Yoda, H.; Takabe, K.; Tanaka, F.; Barbas, C. F. III. J. Am. Chem. Soc. 2006, 128, 4966.

9. Guizzetti, S.; Benaglia, M.; Raimondi, L.; Celentano, G. Org. Lett. 2007, 9, 1247.

10. Palomo, C.; Landa, A.; Mielgo, A.; Oiarbide, M.; Puente, Á; Vera, S. Angew. Chem. 
Int. Ed. 2007, 46, 8431.

11. (a) Luo, S.; Xu, H.; Zhang, L.; Li, J.; Cheng, J.-P. Org. Lett. 2008, 10, 653; (b) Luo, S.; Xu, H.; Chen, L.; Cheng, J.-P. Org. Lett. 2008, 10, 1775.

12. Yang, H.; Carter, R. G. Org. Lett. 2008, 10, 4649.

13. Guillena, G.; Nájera, C.; Viózquez, S. F. Synlett 2008, 3031, and references cited therein.

14. Perlmutter, P. Conjugate Additions in Organic Synthesis; Pergamon: Oxford, 1992.

15. Arai, M.; Miyake, M.; Yamada, M. J. Phys. Chem. C 2008, 112, 1953.

16. Feng, A. S.; Speer, D. V.; DiMagno, S. G.; Konings, M. S.; Streitwieser, A. J. Org. Chem. 1992, 57, 2902.

17. 3f: $\mathrm{p} K_{\mathrm{a}}$ 6.94; 3h, $\mathrm{p} K_{\mathrm{a}}$ 6.37. See Ref 3. See also: (a) Brotzel, F.; Kempf, B.; Singer, T.; Zipse, H.; Mayr, H. Chem. Eur. J. 2007, 13, 336; (b) Wei, Y.; Sastry, G. N.; Zipse, H. J. Am. Chem. Soc. 2008, 130, 3473.

18. (a) Vriezema, D. M.; Aragones, M. C.; Elemans, J. A. A. W.; Cornelissen, J. J. L. M.; Rowan, A. E.; Nolte, R. J. M. Chem. Rev. 2005, 105, 1445; (b) Dwars, T.; Paetzold, E.; Oehme, G. Angew. Chem. Int. Ed. 2005, 44, 7174.

19. Light microscopic studies could not confirm the fact that the reaction occurred in the micelles in water.

20. For the Michael addition reactions in EtOH in the absence of any catalysts, see: Shirakawa, S.; Shimizu, S. Synlett 2007, 3160.

21. As background experiments, in the absence of catalyst $3 \mathbf{d}$ no reaction was observed in water or in $\mathrm{MeOH}$.

22. Typical Experimental Procedure for Michael Addition Reaction in Water. Preparation of $\mathbf{4 b}$. To a stirred solution of methyl cyclopentan-1-one-2-carboxylate (142 mg, 1.0 mmol) and 4-didecylaminopyridine $(37.4 \mathrm{mg}, 0.1 \mathrm{mmol})$ in $\mathrm{H}_{2} \mathrm{O}(2.0 \mathrm{~mL})$ was added methyl acrylate $(172 \mathrm{mg}, 2.0 \mathrm{mmol})$, and the mixture was stirred at $\mathrm{rt}$ for $1.5 \mathrm{~h}$. After the reaction was quenched by the addition of satd $\mathrm{NaHCO}_{3}$, the mixture was thoroughly extracted with AcOEt. The crude product was purified by silica gel column chromatography (elution with hexane/AcOEt $=2: 1$ ) to give $227 \mathrm{mg}(99 \%)$ of $\mathbf{4 b}$ as a colorless oil. 


\section{Table 1}

Catalyst screening results ${ }^{\mathrm{a}}$

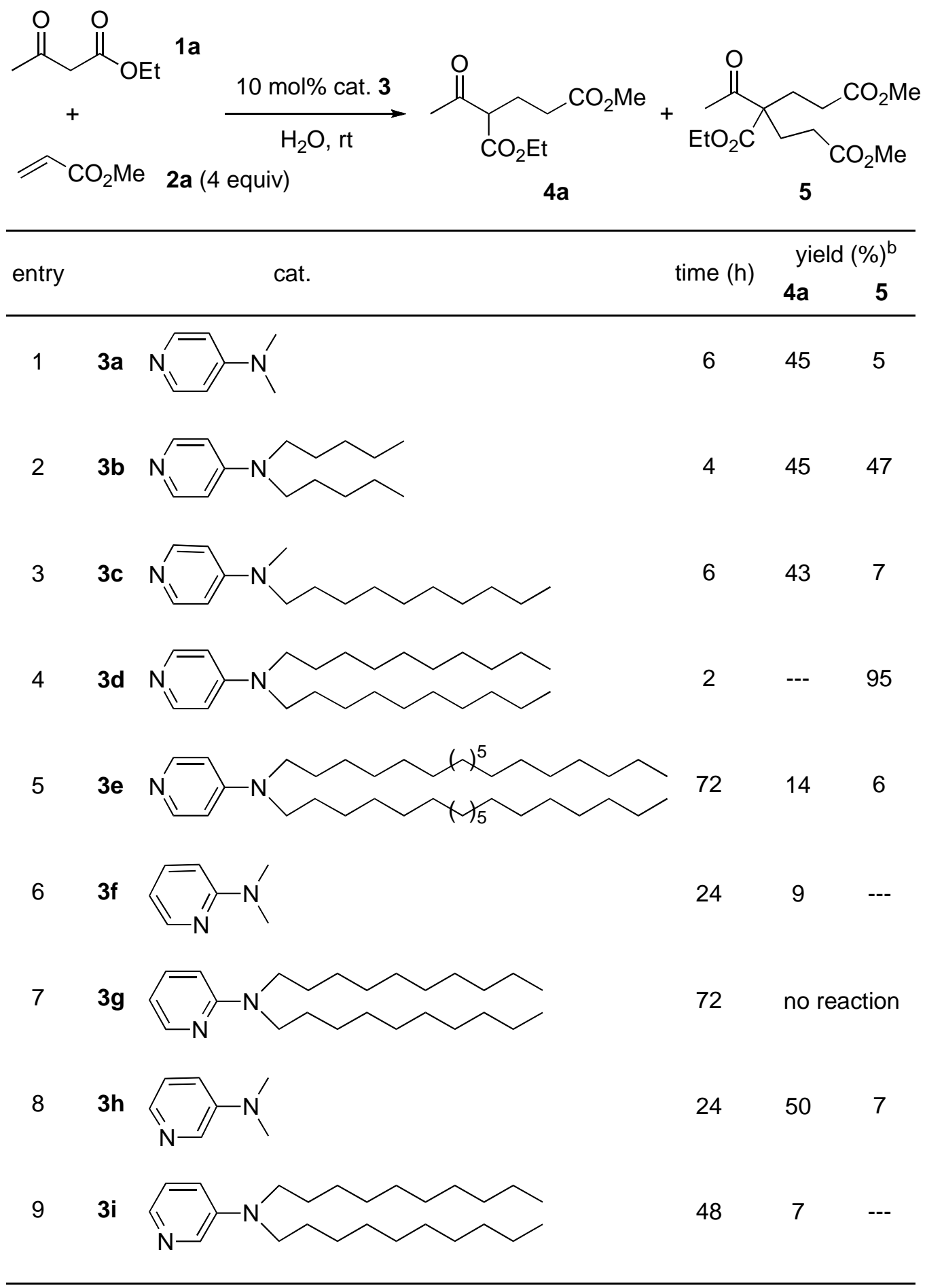

${ }^{\text {a }}$ Reactions carried out at $\mathrm{rt}$ using 1a $(1 \mathrm{mmol})$, 2a $(4 \mathrm{mmol})$, and cat. $(10 \mathrm{~mol} \%)$ in $\mathrm{H}_{2} \mathrm{O}(2$ $\mathrm{mL}$ ).

${ }^{\mathrm{b}}$ Isolated yield. 


\section{Figure 1}

Appearance of a Michael addition reaction (Table 1): (A) no cat., blank; (B) cat. 3a; (C) cat. 3b; (D) cat. 3d, note homogeneous appearence; (E) cat. 3e; (F) cat. 3c. 


\section{Table 2}

Solvent effect ${ }^{\mathrm{a}}$

\begin{tabular}{|c|c|c|c|}
\hline 1b & $\begin{array}{c}\mathbf{2 a} \\
\text { (2 equiv) }\end{array}$ & & $4 b$ \\
\hline entry & solvent & time (h) & yield $(\%)^{b}$ \\
\hline 1 & THF & 52 & 59 \\
\hline 2 & $\mathrm{CH}_{2} \mathrm{Cl}_{2}$ & 30 & 72 \\
\hline 3 & $\mathrm{CH}_{3} \mathrm{CN}$ & 23 & 90 \\
\hline 4 & $\mathrm{MeOH}$ & 2 & 99 \\
\hline 5 & $\mathrm{H}_{2} \mathrm{O}$ & 1.5 & 99 \\
\hline
\end{tabular}

${ }^{\text {a }}$ Reactions carried out using $\mathbf{1 b}(1 \mathrm{mmol})$, 2a $(2 \mathrm{mmol})$, and cat. $3 \mathbf{d}(10 \mathrm{~mol} \%)$ in solvent (2 $\mathrm{mL})$.

${ }^{\mathrm{b}}$ Isolated yield. 
Table 3

Michael addition reaction in water ${ }^{\mathrm{a}}$ 


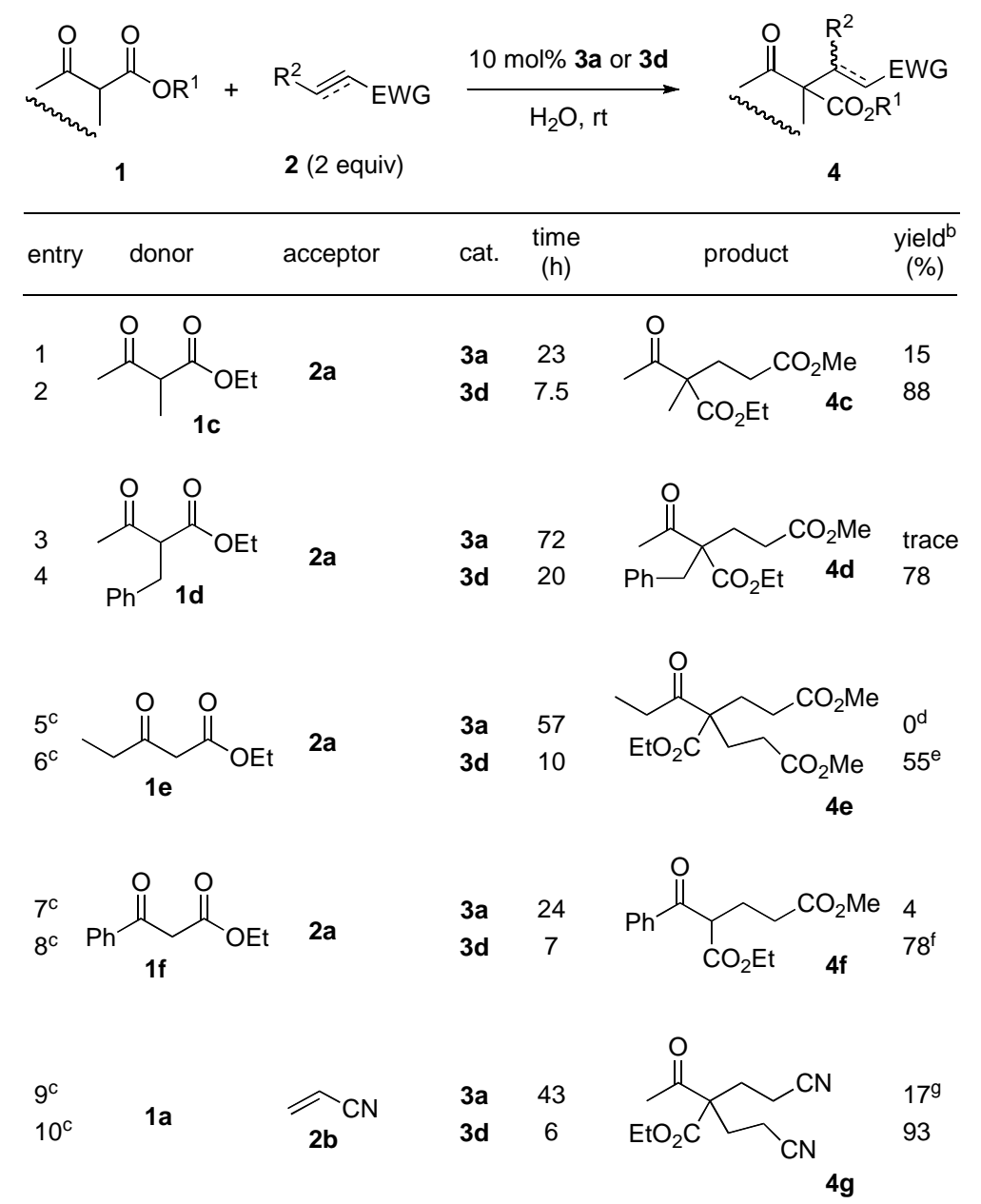

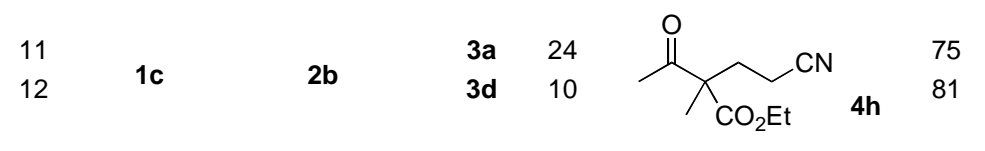

$\begin{array}{llllll}13 & \mathbf{3 a} & 6 & \\ 14 & \mathbf{1 b} & \mathbf{3 d} & 2\end{array}$

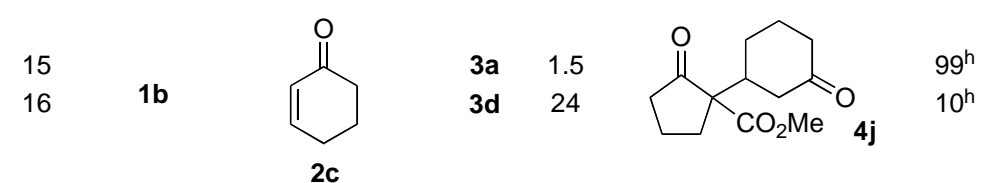<smiles>C#CC(=O)OC</smiles><smiles>CCOC(=O)C1CCCCC1=O</smiles>

$\begin{array}{llll}21 & \mathbf{3 a} & 7 \\ 22 & \mathbf{3 d} & 3.5\end{array}$


${ }^{\mathrm{a}}$ Unless otherwise noted, reactions carried out at $\mathrm{rt}$ using 1 (1 mmol), 2 (2 mmol), and cat. 3a or $3 d(10 \mathrm{~mol} \%)$ in $\mathrm{H}_{2} \mathrm{O}(2 \mathrm{~mL})$.

${ }^{\mathrm{b}}$ Isolated yield.

${ }^{\mathrm{c}} 4$ equiv of 2 was used.

d $13 \%$ of the mono-adduct.

e $39 \%$ of the mono-adduct.

${ }^{\mathrm{f}} 22 \%$ of the double-adduct.

${ }^{\mathrm{g}} 23 \%$ of the mono-adduct.

${ }^{\mathrm{h}} \mathrm{dr}=1: 1$.

${ }^{\mathrm{i}} \mathrm{E} / \mathrm{Z}=1.6: 1$.

${ }^{\mathrm{j}} \mathrm{E} / \mathrm{Z}=1.3: 1$.

${ }^{\mathrm{k}} 100 \mathrm{~mol} \%$ of the catalyst was used.

${ }^{1} \mathrm{E} / \mathrm{Z}=1.1: 1$.

${ }^{\mathrm{m}} E / Z=1.3: 1$. 